\title{
The historical development of McMurdo station, Antarctica, an environmental perspective
}

\author{
ANDREW G. KLEIN†, MAHLON C. KENNICUTT IIt, \\ GARY A. WOLFF $\ddagger$, STEVE T. SWEET $\$$, TIFFANY BLOXOM $\dagger$, \\ DIANNA A. GIELSTRA $\uparrow$ and MARIETTA CLECKLEY \\ $\dagger$ Department of Geography, Texas A\&M University, College Station, TX, USA \\ $\ddagger$ Geochemical and Environmental Research Group, Texas A\&M, College Station, TX, \\ USA \\ §Uniondale High School, Uniondale, New York, USA
}

\begin{abstract}
McMurdo Station is the logistics hub of the United States Antarctic Program, and localized environmental impacts have accompanied its nearly 50 years of continuous operation. An extensive collection of aerial photographs were used to map changes in the buildings, fuel storage tanks, roads, and physically disturbed areas at McMurdo Station since its establishment in 1956. From 1956 and continuing through the 1960s, rapid expansion of the station occurred. From 1970 until present, the area impacted by human activities has increased but at a much decreased rate. Current station operations are largely confined to areas that had already been impacted in the first 10-15 years of the station operations. The spatio-temporal perspective on McMurdo Station's growth provides a baseline from which future changes in the spatial extent of areas impacted by human activities can be monitored as required by the Protocol on Environmental Protection to the Antarctic Treaty.
\end{abstract}

\section{Introduction}

The ice-free southern tip of the Hut Point Peninsula on Ross Island is geographically unique in all of Antarctica (Figure 1). The island's high latitude just 729 nautical miles from the South Pole - and its natural features have made it a compelling and practical location from which to conduct and support exploration and research for over 100 years. From this site in 1902, Robert F. Scott's Discovery expedition staged the first expedition into the Antarctic interior and it supported later British expeditions throughout the heroic period of Antarctic exploration.

The USA began permanent occupation of the site in December 1955, establishing Naval Air Facility McMurdo as a logistics base from which to construct and support a research facility at the geographic South Pole during the 1957-1958 International Geophysical Year (IGY) (Sullivan 1957). Following the IGY, this base, renamed McMurdo Station in 1961, has continued to be the central science and operations facility of the US Antarctic Program (USAP). Located some two kilometers to the east of McMurdo Station is New Zealand's smaller Scott Base which was officially opened on 20 January 1957.

*Corresponding author. Email: klein@geog.tamu.edu (Klein) 


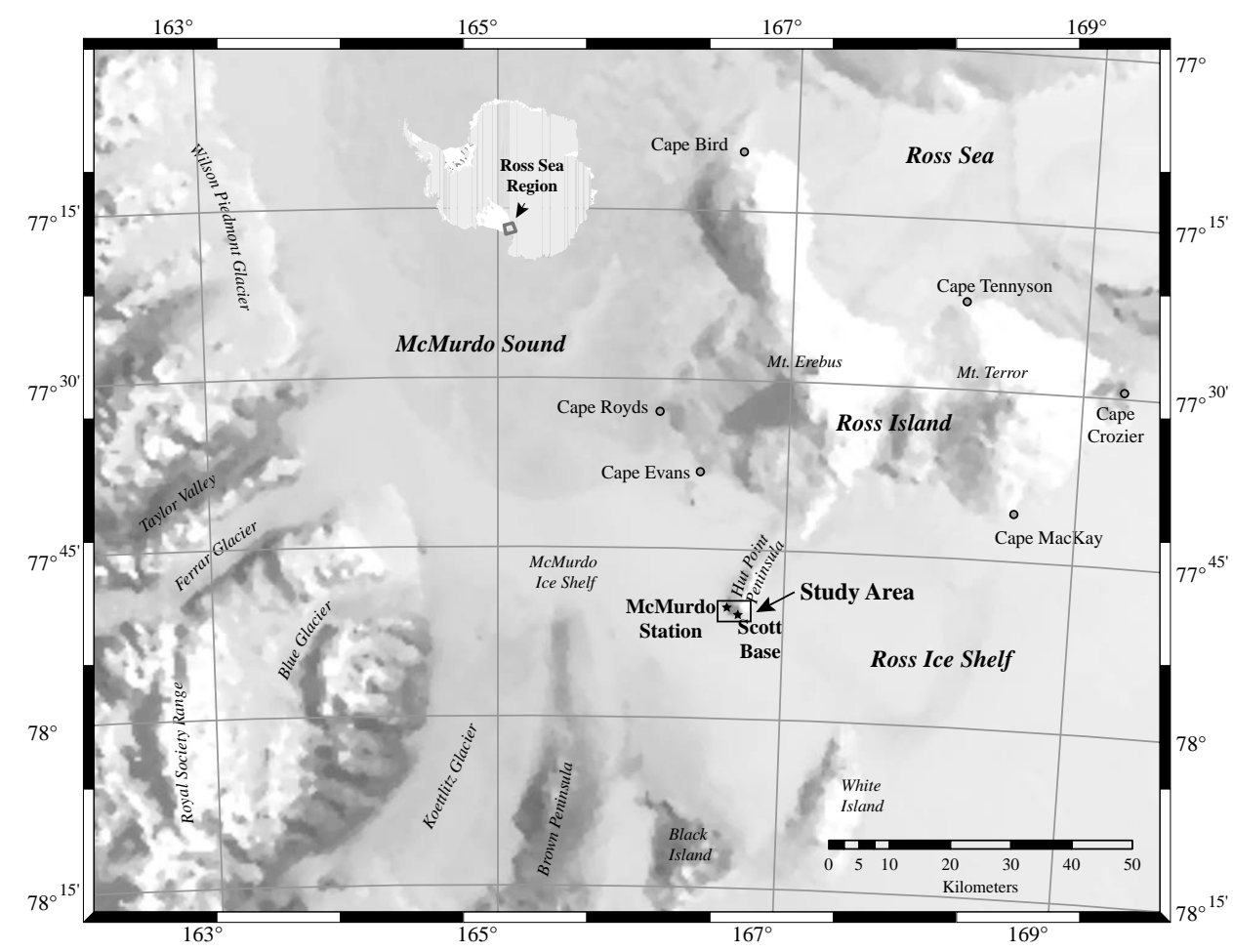

Figure 1. Location map of Ross Island and vicinity. The background image was acquired by the Moderate Resolution Imaging Spectroradiometer (MODIS) on 12 October 2001. The inset map shows the location of Ross Island and McMurdo Station in Antarctica.

Uninhabited by wildlife colonies, a several square kilometer ice-free area with gentle slopes on the Hut Point Peninsula is well-suited to house the increasingly efficient buildings that comprise the McMurdo Station. Its protected natural seaport - Winter Quarters Bay - is the world's southernmost port. Winter Quarters Bay accommodates draft cargo ships and tankers enabling economical import of $95 \%$ of the fuel and cargo used by the USAP in continental Antarctica as well as export of USAP waste from the continent. The sea ice on adjacent McMurdo Sound and glacial ice of the nearby Ross Ice Shelf enables McMurdo to support extensive airlift capabilities both within Antarctica and between McMurdo Station and Christchurch, New Zealand, some 3800 kilometers to the north.

Over its history, McMurdo Station's role in supporting science across the continent has broadened as the magnitude of scientific activity in Antarctica has grown dramatically. Since the late 1960s the number of scientists deploying to Antarctica has nearly quadrupled from approximately 260 to 800 during the 2003-2004 field season (Office of Polar Programs 2003).

Ross Island is ideally situated for conducting and supporting Antarctic science both near and afar. McMurdo provides an enormous amount of logistical support during a typical field season. For example, in the 2003-2004 field season US Air Force and Royal New Zealand Air Force aircraft made 135 round trips between Christchurch and McMurdo. Within the continent, 401 LC-130 round trip transport missions and 122 round trip missions of the smaller Twin Otter aircraft were flown. 
These flights provided support for the Amundesen-Scott South Pole and Vostok Stations and fieldwork throughout the continent (Office of Polar Programs 2003).

In addition to providing support to USAP operations across the continent, McMurdo provides a tremendous amount of support to scientific activities close to the station and in the broader McMurdo Sound region. In 2003-2004, 321 helicopter flight hours supported 112 groups or activities (Office of Polar Programs 2003) including a host of geological and biological studies within the Transantarctic Mountains and McMurdo Dry Valleys at a Long-Term Ecological Research (LTER) site.

McMurdo serves a vital role in the USAP's environmental stewardship of the continent. It is the centralized location with the physical space, specialized facilities, and trained personnel capable of receiving and processing waste from throughout Antarctica. At McMurdo, waste is sorted, identified, packed and shipped for appropriate recycling or disposal in the USA. The logistical support McMurdo provides for the USAP enables scientific research to be conducted throughout the continent with a high level of environmental stewardship. Standards of waste management in Antarctica have increased and now require the removal of all solid and hazardous waste from the continent. Activities at McMurdo enable the recycling of approximately $65 \%$ of the material removed from Antarctica by the USAP (Office of Polar Programs 2003).

Fifty years of operation of McMurdo Station and Scott Base has not been without localized environmental impacts. McMurdo Station has had a much larger environmental impact than the much smaller Scott Base. Fortunately, the impact of human activities is localized around these permanent stations (Waterhouse 2001).

Conduct and activities that take place in Antarctica are governed by the Antarctic Treaty (402 UNTS. 71; TIAS 4780). The Treaty reserves the region south of $60^{\circ} \mathrm{S}$ latitude and the Antarctic continent for peaceful purposes and fosters international cooperation in scientific research. It was signed on 12 January 1959 by 12 countries and went into effect on 23 June 1961. In 2006, 45 countries adhered to the treaty. Among the original treaty provisions are preservation and conservation of living resources in Antarctica (US Department of State, "Antarctic Treaty." Art. IX). Three additional Antarctic Treaty conventions relating to the protection of Antarctica's natural environment have been adopted.

The Protocol on Environmental Protection to the Antarctic Treaty (XI ATSCM/2) was adopted in October 1991 and went into force in 1998. This Protocol requires that activities be planned and conducted to limit adverse environmental impacts. In planning activities sufficient information needs to exist to allow prior assessments of, and informed judgments about, possible environmental impacts. (US Department of State, "Protocol" Art. 3). The protocol also calls for regular and effective environmental monitoring to assess the impact of ongoing activities, to verify predicted impacts, and to facilitate early detection of unforeseen effects (US Department of State "Protocol." Art. 3). The protocol also specifies and outlines required steps for environmental impact assessment and appropriate monitoring of key environmental indicators. Especially pertinent to this research is the requirement that all proposed activities with "more than a minor or transitory impact" undergo a comprehensive environmental evaluation. Part of the evaluation is " $a$ description of the initial environmental reference state with which predicted changes are to be compared and a prediction of future environmental reference state in the absence of the proposed activity..." (US Department of State, "Protocol." Art. 3). 
Although the protocol did not go into effect until 14 January 1998, on 2 October 1996, the Antarctic Science, Tourism, and Conservation Act of 1996 (PL 104-227), was signed into law and applies the Protocol on Environmental Protection to the Antarctic Treaty to US Antarctic activities. Thus the USAP adopted the spirit of the protocol shortly after the treaty was signed in Madrid in 1991 and began complying with the protocol's environmental provisions.

As part the USAP's compliance, a three-year environmental monitoring pilot project for McMurdo Station was developed and current monitoring is ongoing. This program was based on the outcomes of a series of national and international workshops and a year of planning. As the location of the largest human presence in Antarctica, McMurdo Station was chosen as best suited to test the fundamental assumptions underpinning a long-term monitoring program. It is the intent of USAP that the principles and lessons learned at McMurdo Station be applied to all operations and science activities, as appropriate, throughout USAP facilities in Antarctica.

The goals of the McMurdo Station monitoring program are multi-faceted with a primary goal of establishing the aerial extent of the disturbance zones associated with McMurdo Station and its activities (e.g. its "footprint"). Once the present footprint(s) of the station are defined, the intent is to objectively determine whether or not the impacted area is increasing, decreasing or is remaining static over time. These observations will provide feedback to management through reliable and quantitative assessments concerning the effectiveness of management decisions in limiting adverse environmental impacts of station activities.

To understand the current observed patterns of human impact at McMurdo, a spatio-temporal perspective on the station's activities was developed. This perspective provides important clues on the current environmental state of the station as sampled by the pilot environmental monitoring program. The spatio-temporal perspective will be used to assess whether observed environmental impacts are the result of current operational practices or are the legacy of former practices that occurred early in the station's history. It will also provide a baseline from which to determine whether future station activities increase or decrease McMurdo Station's footprint.

The spatio-temporal perspective of human impact was developed by integrating the extensive aerial photographic archive available for McMurdo within a geographic information system (GIS). Historical changes in major station activities were identified in the imagery including: buildings, fuel tanks, road network, generalized land use and physical disturbance of the surface. The aerial photography mapping was augmented by available station maps and documents and through interviews with station personnel. Mapping station changes over time creates a detailed picture of the historical development of McMurdo and provides a reference state from which to measure future change.

While this paper examines how science support activities at McMurdo Station have altered the station's 'footprint' through time, it is important to recognize that these activities impact a relatively small area. In addition, growth in the area impacted by human activities at McMurdo has not increased uniformly through time. Rather as this research documents, McMurdo expanded rapidly in the 1950s and 1960s and since that time the area impacted by human activities has grown at a much slower rate. In addition, environmental stewardship has increased across the USAP. Operational activities at McMurdo today have lower environmental impacts 
than practices used early in the station's history. Moreover, activities conducted at McMurdo increasingly enable scientific research to be conducted across the Antarctic continent in a manner consistent with the utmost environmental stewardship.

\section{Physical setting}

The geographic location (Figure 1) and physiography of the Hut Point Peninsula made it uniquely suited to play an important role in Antarctic exploration and research from the heroic era to the present day. As the Ross Ice Shelf impinges upon Ross Island just to the east of Pram Point (Figure 2), Winter Quarters Bay marks the southernmost landfall possible. Because of its location, Robert Falcon Scott selected the sheltered bay as the overwintering location of the National Antarctic (Discovery) Expedition. Sea ice does not always annually break up near Hut Point, hence later British expeditions were forced to locate bases farther north on Ross Island at Cape Evans and Cape Royds. Today, Winter Quarters Bay remains a viable port with Coast Guard icebreakers assuring access regardless of ice conditions in McMurdo Sound. This enables annual resupply of the station and removal of waste material in ice-strengthened tankers and container vessels.

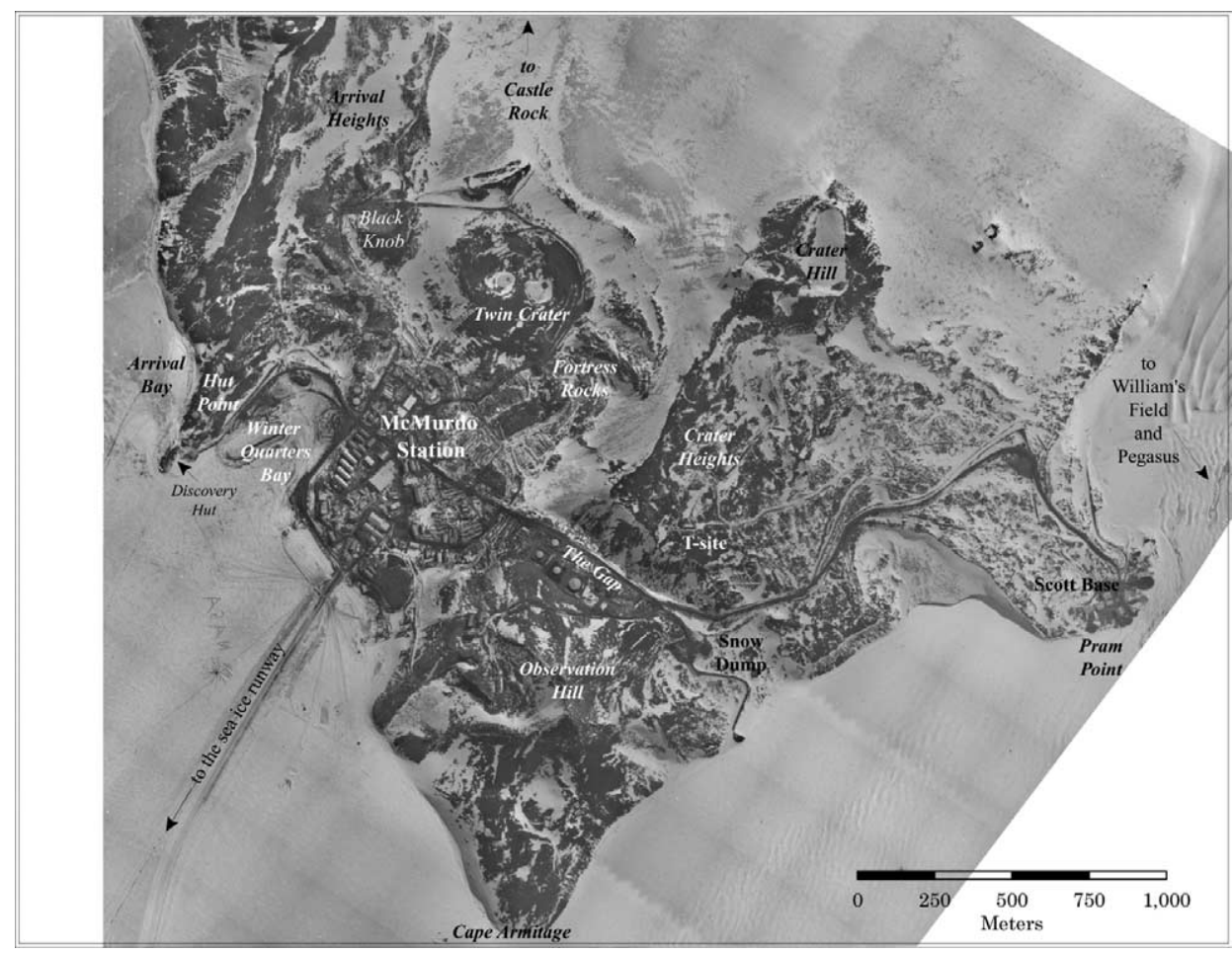

Figure 2. Aerial photograph of the southern tip of the Hut Point Peninsula showing the location of McMurdo Station and Scott Base. Physiographic features, most originally named by the Discovery Expedition, are shown in italics. The orthorectified aerial photograph was produced by the International Centre for Antarctic Information and Research (ICAIR) from aerial photography acquired in November 1993. 
McMurdo Station is situated in a low lying, and relatively protected, area immediately adjacent to Winter Quarters Bay. This area is bounded by higher topographic features to the north and east, including Observation Hill, Crater Hill, Twin Craters, and Arrival Heights (Figure 2). Most of the station's infrastructure lies at altitudes below the highest point in The Gap (approximately 61 meters above sea level) and most of central McMurdo is located at altitudes below $40 \mathrm{~m}$. Some buildings, fuel storage and cargo storage extend to altitudes of $100 \mathrm{~m}$ and communication and radar tracking infrastructure lies on higher plateaus. Scott Base is approximately $2 \mathrm{~km}$ to the east and is accessible by the Scott Base road which runs through The Gap. In addition to the station facilities located on land, the USAP maintains three airfields outside McMurdo station proper. There is a sea ice runway and two runways, Williams Field and Pegasus, located on the Ross Ice Shelf.

Surface cover at McMurdo is a contrasting mix of dark volcanic rock, primarily basalt, with high albedo snow and ice. Snow extent varies considerably over the course of a year. With the exception of a flow banded trachyte at Observation Hill (Cole et al. 1971) all the local bedrock is basalt. The local area as described by H.T. Ferrar, Geologist to the National Antarctic Expedition was "About four square miles of bare rock, entirely of volcanic origin was the only land within walking distance of the 'Discovery's' Winter Quarters and therefore did not offer a promising field of discovering the geological history of South Victoria Land." (Ferrar 1905). As illustrated in Figure 3, much of the surface of the McMurdo area was originally covered by a ubiquitous periglacial feature - a microrelief pattern of polygons (Péwé 1959; Taylor 1922).

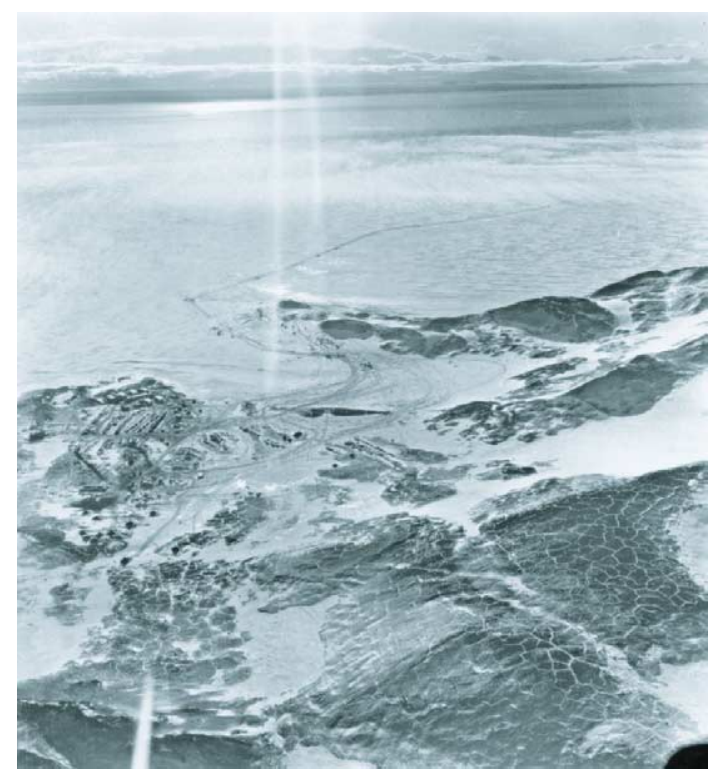

Figure 3. Oblique Trimetrogon aerial photograph (TMA 475 frame 66) of Naval Air Facility McMurdo taken in February 1956. 


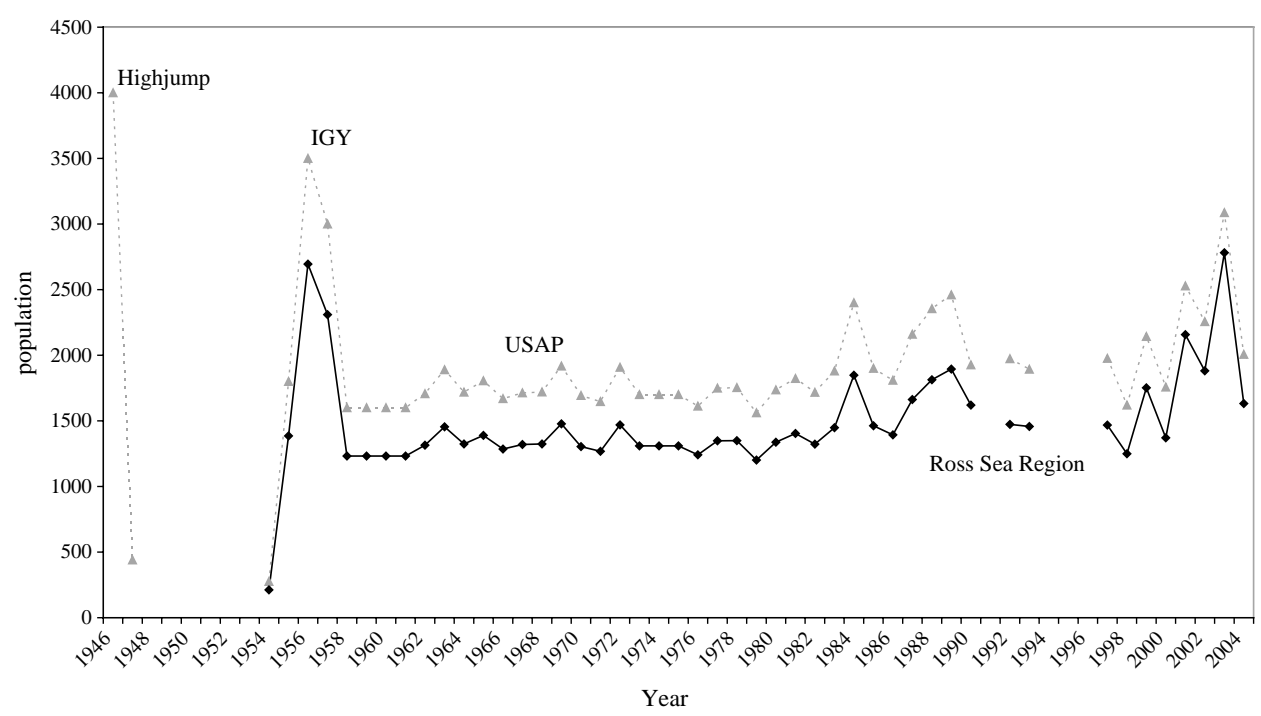

Figure 4. USAP and Ross Sea Region Population. Populations prior to the 1989-1990 season are taken from Beltramino (1993). More recent population totals are taken from annual Antarctic Treaty Information Exchange documents (http://nsf.gov/od/opp/antarct/ treaty/index.htm). The Ross Sea Region's population includes all USAP personnel with the exception of those at Palmer Station and aboard ships.

\section{Early history}

Human impacts on the Hut Point Peninsula preceded construction of the area's two permanent stations. Ross Island (Figure 1) has a long rich history of exploration; it surpasses any other area in Antarctica in the number of historical events that have occurred in its vicinity (Neider 1974). Ross Island was discovered by, and is named after, James Clark Ross, who first sighted the island on 26 January 1841 (Ross 1847). However, the island remained unvisited by humans until 21 January 1902 when Robert Falcon Scott's Discovery Expedition entered McMurdo Sound and made landfall on Ross Island at Cape Crozier. On 2 February 1902, Hut Point was selected as the site for the expedition's "winter quarters" (Scott 1905) and the protected bay first used by Scott now serves as McMurdo's port.

During February and March of 1902 Ross Island's first structure, the historic Discovery Hut, was constructed. This hut would service future British expeditions, including Earnest Shackleton's Nimrod expedition (Shackleton 1909) and Scott's final expedition. The British Antarctic Expedition of 1910-1913 reached McMurdo Sound in January of 1911, but ice conditions prevented reoccupation of the peninsula forcing Scott to establish a new camp at Cape Evans some $25 \mathrm{~km}$ to the north. Later, the Discovery Hut supported the laying of depots from Ross Island to the foot of Beardmore Glacier by members of Shackelton's British Imperial Trans Antarctic Expedition. The heroic age ended on Ross Island following the departure of Shackelton and the Aurora from Ross Island on 17 January 1917, after Shackleton had returned to McMurdo Sound to rescue the depot laying crew that had been in the Ross Sea region since January 1915. According to Shackleton's observations in 1917, the Discovery Hut was still in as good a condition as it was in 1902 (Shackleton 1919). 
In February 1947, members of the USA Navy's Operation Highjump arrived to explore the possible establishment of an auxiliary base. One year later, members of Operation Windmill also toured Ross Island's historical huts (Neider 1974). The Hut Point Peninsula would remain unoccupied until 1955 when Operation Deep Freeze I established the permanent base that was to become McMurdo Station.

Prior to the 1955-1956 austral summer, the only buildings occupying the current site of McMurdo station were the historic Discovery Hut and two smaller buildings constructed to house the magnetic instruments of Scott's Discovery expedition (Scott 1905). Writing on 18 July 1902, Robert Scott described the scene at Hut Point:

Beyond the large hut stand the smaller magnetic huts and from the eminence on that point the little cluster of buildings looks quite imposing. In the midst of these vast ice-solitudes and under the frowning desolation of the hills, the ship, the huts, and busy figures passing to and fro, and the various other evidences of human activity are extraordinarily impressive. How strange it all seems! For countless ages the great somber mountains about us have loomed through the gloomy polar night with never an eye to mark their grandeur, and for countless ages the windswept snow has drifted over these great deserts with never a footprint to break its white surface; for one brief moment the eternal solitude is broken by a hive of human insects; for one brief moment they settle, eat, sleep, trample, and gaze, then they must be gone and all must be surrendered again to the desolation of the ages. (Scott 1905)

Since 1955, the Hut Point Peninsula has supported a permanent human presence and has remained the major center of human activity on the continent.

\section{Early development of McMurdo Station}

The erection of buildings on the Hut Point Peninsula as part of USA Antarctica efforts began in December 1955 as Operation Deep Freeze I established a base for planned scientific activities during the IGY of 1957-1958. The initial base was originally called Naval Air Facility McMurdo and was named after Archibald McMurdo, a lieutenant on James Clarke Ross's ship Terror. Initial habitation consisted of tents scattered on the land and sea ice immediately adjacent to the historic Discovery Hut.

Early in 1956, a set of prefabricated structures was erected and "downtown" McMurdo station arose across Winter Quarters Bays from the Discovery Hut (Figure 3). As described by Neider (1974) "The early form of the station comprised some thirty buildings including the kennels, a parachute loft, an inflation shelter, VIP quarters and a hut designated as "Aerology." One of the eastern-most buildings was the Quonset chapel." These prefabricated structures were in the same place as the current "town" center and, like today, cargo facilities occupied areas upslope of the station center. Thus, the current configuration of McMurdo was established at its initial construction. By 1960, 90 recognizable structures occupying an area of approximately $11,000 \mathrm{~m}^{2}$ had been constructed. In 1961 Naval Air Facility McMurdo was renamed as McMurdo Station (Neider 1974). Continuous operations began in 1956 and the station has grown into the largest year-round operational base in Antarctica. 


\section{Methodology}

\subsection{Aerial photography}

The US Geological Survey (USGS) holds the world's largest collection of Antarctic photography. The archive consists of over 300,000 frames stored at the USGS's EROS Data Center in Sioux Falls, SD. The collection begins in 1946 and is composed primarily of panchromatic photographs; however, natural color and color-infrared (CIR) photographs have been acquired more recently.

From 1946 to 1975 , aerial photography by the USAP was acquired using the trimetrogon method in which three cameras simultaneously take left oblique, vertical, and right oblique photographs to provide a horizon-to-horizon view. Since 1975, most Antarctic aerial photography has employed a single vertical camera. Despite this change, aerial photographs in the library continue to be referenced by their Trimetrogon Aerial photography (TMA) number (http://edc.usgs.gov/products/aerial/scar.html).

Because of McMurdo Station's importance to US operations, photography of the station itself is plentiful and begins in February 1956, a few months after the station's establishment. The subset of images used in this study is shown in Table 1. Although the photography varies in scale, quality, and spatial extent, it provides a unique historical perspective capturing McMurdo's development. The possibility of using aerial photography for environmental monitoring at McMurdo was identified by Jezek and Onstott (1999). They assessed the role remote sensing can play in environmental monitoring in Antarctica, and their work drew heavily on aerial photography of McMurdo Station. Their work serves as a valuable guide to the extensive number of features at McMurdo that can be identified on aerial photography.

Only major features (buildings, fuel tanks, roads and disturbed area) are mapped in this research due to ease in their identification. Mapping these features over McMurdo's history enabled development of a record of environmental change in McMurdo Station both within the central portion of the station and, when permitted by the available images, the entire southern portion of the Hut Point Peninsula. The developed record varies considerably from year to year in the number of photographs and their scale and quality.

Suitable aerial photographs (Table 1), both vertical and oblique, were digitized at a resolution of 600 dots per inch on a standard flatbed scanner. This resolution translated into pixel ground resolutions ranging from less than a meter to several meters depending on the original scale of the photographs. Consequently, not all photographs could be used to identify all features. Selected images were clipped to remove the annotation surrounding the aerial photographs. Images along individual flightlines were mosaiced through simple visual alignment. Depending on the date, single images or mosaiced strips were then georeferenced to the 22 November 1993 orthophotograph created by the International Centre for Antarctic Information and Research (ICAIR).

Large differences in annual and seasonal changes in snow extent as well as anthropogenic landscape modification and infrastructure meant that many of the individual large-scale $(\geq 1: 5000)$ photographs lacked features that could be unambiguously distinguished between acquisition dates. This made coregistration of individual large-scale aerial photographs, especially in areas outside of central 
Table 1. Aerial photographs and satellite images used in the study and what features were mapped on individual days.

\begin{tabular}{|c|c|c|c|c|c|c|c|c|}
\hline \multirow[b]{2}{*}{ Date } & \multicolumn{4}{|c|}{ Image information } & \multicolumn{4}{|c|}{ Mapping information } \\
\hline & TMA & Altitude & Orientation & Source & Buildings & Fuel tanks & Roads & Disturbance \\
\hline $2 / 1 / 1956$ & $467 / 457$ & Unknown & Oblique & USGS & & & & \\
\hline $11 / 14 / 1959$ & 549 & 6000 & Vertical & USGS & & $\sqrt{ }$ & & $\sqrt{ }$ \\
\hline $11 / 14 / 1959$ & 554 & 16,000 & Vertical & USGS & & & & \\
\hline $2 / 15 / 1960$ & 590 & 1300 & Vertical & USGS & $\sqrt{ }$ & $\sqrt{ }$ & $\sqrt{ }$ & $\sqrt{ }$ \\
\hline $1 / 27 / 1962$ & 950 & 2800 & Vertical & USGS & $\sqrt{ }$ & $\sqrt{ }$ & & $\sqrt{ }$ \\
\hline $11 / 9 / 1962$ & $1095 / 1097$ & 5000 & Vertical & USGS & & & & $\sqrt{ }$ \\
\hline $12 / 31 / 1962$ & $1124 / 1130$ & 5000 & Vertical & USGS & $\sqrt{ }$ & $\sqrt{ }$ & $\sqrt{ }$ & $\sqrt{ }$ \\
\hline $11 / 2 / 1963$ & 1208 & 15,000 & Vertical & USGS & & & & \\
\hline $11 / 4 / 1963$ & $1219 ?$ & 15,000 & Vertical & USGS & & & & \\
\hline $11 / 10 / 1964$ & 1454 & 5000 & Vertical & USGS & & & & $\sqrt{ }$ \\
\hline $1 / 22 / 1965$ & $1592 / 1593 / 1594$ & 2800 & Vertical & USGS & & & & \\
\hline $1 / 26 / 1965$ & $1565 / 1567 / 1568$ & 2800 & Vertical & USGS & $\sqrt{ }$ & $\sqrt{ }$ & & $\sqrt{ }$ \\
\hline $2 / 18 / 1965$ & 1615 & 2800 & Vertical & USGS & $\sqrt{ }$ & $\sqrt{ }$ & $\sqrt{ }$ & $\sqrt{ }$ \\
\hline $2 / 18 / 1965$ & 1648 & 15,000 & Oblique & USGS & & & & \\
\hline $10 / 27 / 1965$ & 1703 & 9700 & Oblique & USGS & & & & \\
\hline $1 / 19 / 1967$ & 1842 & 12,000 & Oblique & USGS & & & & \\
\hline $11 / 20 / 1967$ & 2044 & 32,000 & Vertical & USGS & & & & $\sqrt{ }$ \\
\hline $11 / 28 / 1969$ & 2225 & 9000 & Vertical & USGS & & & & $\sqrt{ }$ \\
\hline $1 / 25 / 1970$ & 2256 & 2500 & Vertical & USGS & $\sqrt{ }$ & $\sqrt{ }$ & & \\
\hline $1 / 21 / 1971$ & 2306 & 5000 & Vertical & USGS & & $\sqrt{ }$ & & \\
\hline $1 / 27 / 1974$ & $2371 / 2428 / 2429 / 2430 / 2431 / 2432$ & 2500 & Vertical & USGS & $\sqrt{ }$ & $\sqrt{ }$ & & $\sqrt{ }$ \\
\hline $2 / 5 / 1975$ & $2330 / 2331 / 2332 / 2333$ & 3200 & Vertical & USGS & $\sqrt{ }$ & $\sqrt{ }$ & $\sqrt{ }$ & $y$ \\
\hline $2 / 9 / 1980$ & 2458 & 4500 & Vertical & USGS & $\sqrt{ }$ & $\sqrt{ }$ & & $\sqrt{ }$ \\
\hline $1 / 22 / 1983$ & 2491 & 4500 & Vertical & USGS & $\sqrt{ }$ & $\sqrt{ }$ & & $\sqrt{ }$ \\
\hline $12 / 9 / 1983$ & 2373 & 2000 & Vertical & USGS & $\sqrt{ }$ & $\sqrt{ }$ & & \\
\hline $12 / 9 / 1983$ & 2573 & 3,200 & Vertical & USGS & & & & \\
\hline $12 / 15 / 1983$ & 2690 & 26,000 & Vertical & USGS & & & & \\
\hline $12 / 28 / 1983$ & 2691 & 4500 & Vertical & USGS & & $\sqrt{ }$ & & $\sqrt{ }$ \\
\hline $11 / 12 / 1984$ & 2821 & 15,900 & Vertical & USGS & & & & \\
\hline $1 / 16 / 1985$ & 2772 & 4300 & Vertical & USGS & $\sqrt{ }$ & $\sqrt{ }$ & $\sqrt{ }$ & $\sqrt{ }$ \\
\hline
\end{tabular}


Table 1. Continued.

\begin{tabular}{|c|c|c|c|c|c|c|c|c|c|}
\hline \multirow[b]{2}{*}{ Date } & \multicolumn{5}{|c|}{ Image information } & \multicolumn{4}{|c|}{ Mapping information } \\
\hline & & TMA & Altitude & Orientation & Source & Buildings & Fuel tanks & Roads & Disturbance \\
\hline $11 / 6 / 1989$ & 2865 & & 5000 & Vertical & USGS & & $\sqrt{ }$ & & $\sqrt{ }$ \\
\hline $1 / 11 / 1989$ & 2980 & & 15,000 & Vertical & USGS & & $\sqrt{ }$ & & \\
\hline $11 / 22 / 1993$ & & & 2500 & Vertical & ICAIR & $\sqrt{ }$ & $\sqrt{ }$ & $\sqrt{ }$ & $\sqrt{ }$ \\
\hline $11 / 22 / 1993$ & & & 10,000 & Vertical & ICAIR & & & & \\
\hline $11 / 23 / 1993$ & 3101 & & 3000 & Vertical & USGS & & & & \\
\hline 2/2/1999 & 3199 & & 3000 & Vertical & USGS & $\sqrt{ }$ & $\sqrt{ }$ & & $\sqrt{ }$ \\
\hline $1 / 1 / 2000$ & & & & Vertical & USGS & $\sqrt{ }$ & $\sqrt{ }$ & $\sqrt{ }$ & $\sqrt{ }$ \\
\hline $11 / 20 / 2001$ & & & Satellite & Vertical & DIGITAL GLOBE & $\sqrt{ }$ & $\sqrt{ }$ & & $\sqrt{ }$ \\
\hline $1 / 1 / 2003$ & & & & Vertical & DIGITAL GLOBE & $\sqrt{ }$ & $\sqrt{ }$ & & \\
\hline $10 / 15 / 2005$ & & & & Vertical & DIGITAL GLOBE & $\sqrt{ }$ & $\sqrt{ }$ & & \\
\hline
\end{tabular}


McMurdo, difficult and in some cases impossible. This problem was greatest for images acquired early in the station's history.

Due to problems in locating ground control points in areas outside of the station, a conservative approach to georectification was taken. A first or second order polynomial warp was used to georegister images. Delaunay triangulation (Peucker et al. 1978) was also attempted and worked well for central McMurdo. However, outlying areas often had insufficient numbers and poor distributions of ground control points for successful application of the technique. For the purposes of this study, the time and cost required for orthorectification of a large number of images was unwarranted. With the selected geolocation technique, depending on the location and scale of the features, displacement of features in the center of McMurdo was several meters or more in central McMurdo and was greater in outlying areas. Despite geocoding inaccuracies, a suitable image archive was produced.

In addition to aerial photography, high-resolution commercial satellites, such as Quickbird, now provide the submeter panchromatic resolution views of the station required to document station changes over time. A preliminary reduced resolution Quickbird Image acquired on 20 November 2001 over McMurdo is publicly available (http://www.robins.ball.com/qb_im_intro.html) and is of suitable quality for mapping fuel tanks and buildings. Additional Quickbird satellite images, acquired for McMurdo in 2003 and 2005, have proven to be of sufficient quality for detailed mapping and have provided a cost-effective alternative to aerial photography for environmental monitoring.

\subsection{Geographic information systems (GISs)}

In a GIS, the georeferenced aerial photographs were used as a mapping base to map buildings, fuel tanks, roads, land usage, and disturbed areas. Because of the quality and scale of the available aerial photographs, not all features could be mapped on all images. Table 1 shows the features mapped for each acquisition.

Mapping was completed on an individual image basis. In cases where ambiguity existed or the spatial coverage was incomplete, earlier and later images were consulted to deduce a structure's presence or absence on a certain date. Station maps were also consulted in this process. The mapping of roads, disturbed areas, and land use is by necessity a subjective process. Ground observations of the McMurdo area made during extensive field sampling efforts provided a high degree of local knowledge which guided the mapping.

A comprehensive mapping of disturbance at McMurdo Station through time was also undertaken. In mapping physical disturbance at the station, a hexagonal grid composed of individual $50 \mathrm{~m}$ diameter hexes was overlaid on the immediate area. All georectified photographs were then examined in sequential order. The date of initial disturbance was then recorded for each hexagon. This provided a chronology of the approximate first date when areas in and around McMurdo were first affected by significant enough human disturbance to be visible on an aerial photograph.

\section{Station population}

The USAP is the largest in the history of Antarctic science and exploration. Over the last 50 years, approximately 70,000 personnel have traveled to the Ross Sea Region 


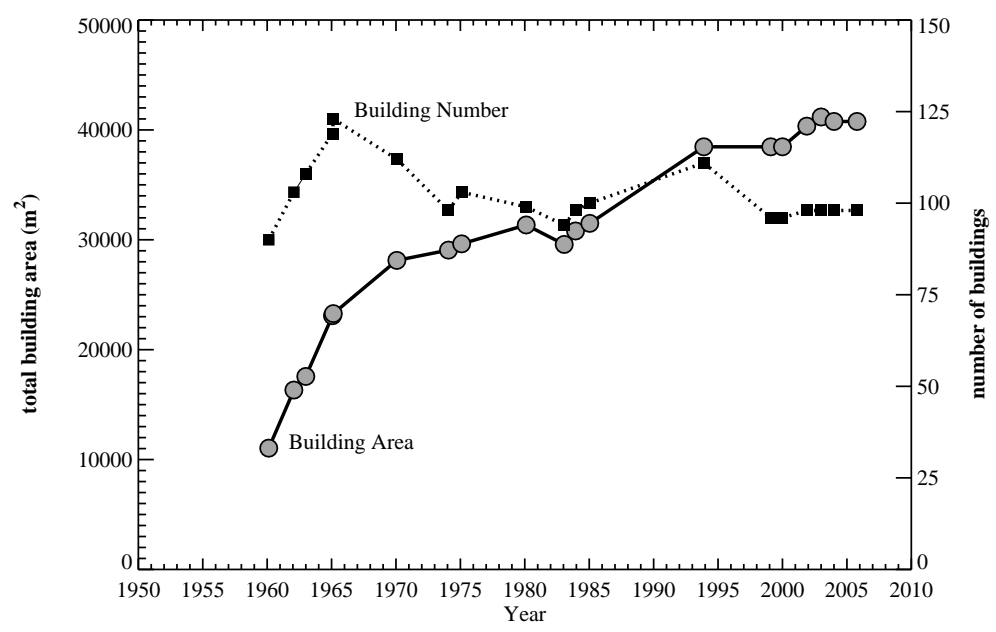

Figure 5. Area (gray circles) and number (black squares) of buildings at McMurdo Station as determined from aerial photography.

for science and support (Beltramino 1993; Harris 2001). Figure 4 shows the number of individuals in the USAP and the number of USAP individuals within the Ross Sea region. The number of USAP individuals considered to be in the Ross Sea Region includes individuals working both within the area and those transiting through to South Pole Station and other field camps. Alternatively, the Ross Sea region total can be considered all USAP personnel that season exclusive of those aboard ships and at Palmer Station.

The region's population (Figure 4) peaked in 1957-1958 during the IGY at approximately 3500 . From 1959 to the mid 1980s, the station's summer population remained fairly constant, fluctuating between 1200 and 1500. The population increased slightly during the late 1980s. Both USAP and the USAP Ross Sea Region population grew from 1997 through 2003. From 2000 to the 2004/2005 season, the USAP and Ross Sea Region populations have increased and fluctuated. The 2003/ 2004 season had the largest population since the IGY with USAP totals of 3000 individuals and the Ross Sea Region population of nearly 2800. The number of overwintering personnel is much lower. During the period 1956-2005 the station's overwintering population ranged from just 50 people to over 250 .

\section{Physical structures}

The US Navy's 1961, Preliminary Study for Reconstruction and Improvement of US Naval Air Facility, McMurdo, Antarctica, described future station plans. The plan called for the construction of a compact station of 58 buildings where facilities with related functions would be in close proximity. The proposed station could house 1500 summer and 500 overwintering personnel. With the exception of a substantial housing and dining facility and several warehouses, the development of McMurdo Station did not follow this plan. Rather, McMurdo was developed on a project-byproject basis (ASA 1999). A second planning effort, the Long Range Development Plan, Antarctica focused on replacing existing small, temporary structures with larger, more efficient ones and consolidating buildings in already developed areas 
(ASA 1999). As evidenced in the aerial photography archive, station development since 1979 has generally followed this approach.

Temporal changes in the number and area of buildings over the station's history are shown in Figure 5. The number of buildings, especially early in the station's history, is approximate. Some McMurdo structures are small and are easily confused with storage containers. Especially early in the station's history, it can also be unclear whether two connected buildings should be counted as one or two separate buildings. The increase in building numbers in 1993 is due in part because the 1993 building coverage was created by ICAIR rather than our own mapping efforts. Regardless of these small issues, the aerial photographic record provides a robust record of changes in building area over most of the station's history.

Two temporal trends are clear. First, the area covered by buildings at McMurdo has increased markedly over time. Second, the total number of buildings has remained relatively stable, perhaps decreasing somewhat after a peak in the mid 1960s. The area occupied by buildings has not increased monotonically over the station's history but rather, a rapid construction phase occurred from 1956 to 1970. At the end of this period, the area occupied by structures reached approximately $28,000 \mathrm{~m}^{2}$ (Figure 5). From the early 1970s through the late 1980s, the area occupied by structures remained relatively constant. Smaller buildings were replaced with new and improved housing facilities. A second period of growth occurred in the 1990s with the construction of new dormitories and the Crary Science Lab. The station's growth continued into the current decade with the creation of two new science support facilities that eventually will replace several older buildings including the venerable Berg Field Center (BFC). From a visual perspective the removal of many of the station's original smaller structures and their replacement with larger ones has resulted in the station appearing to have become more organized over time.

Figure 6 shown the station at four times during its history. While the actual building footprint has increased substantially through time, this increase has not been accompanied by an increase in the overall disturbed area. By the end of December 1962 (Figure 6a), buildings had been constructed in all areas where they currently exist. Since that time, construction at McMurdo has been characterized by the following patterns:

1. Construction of storage and maintenance facilities in former cargo storage areas located north of the McMurdo-Scott Base Road;

2. Infilling of areas between existing buildings south of the McMurdo-Scott Base Road by new structures; and

3. Beginning in earnest in the 1980s and continuing to the present, removal of small buildings and reoccupation of these building sites with larger and more efficient structures.

Some areas of the station have experienced a contraction of buildings. The nuclear reactor on Observation Hill was disassembled during the 1974-1975 austral summers. As part of the Hut Point remediation, the pump house and associated piping were removed during the 1996-1997 austral summer leaving the historic Discovery Hut as the only extant building. The removal of the remaining two buildings on Observation Hill remains a priority in McMurdo's long-term research plan (Erb 1999). While new building activity has occurred at the T-site, this area has already been the site of several buildings (Figure 2). 


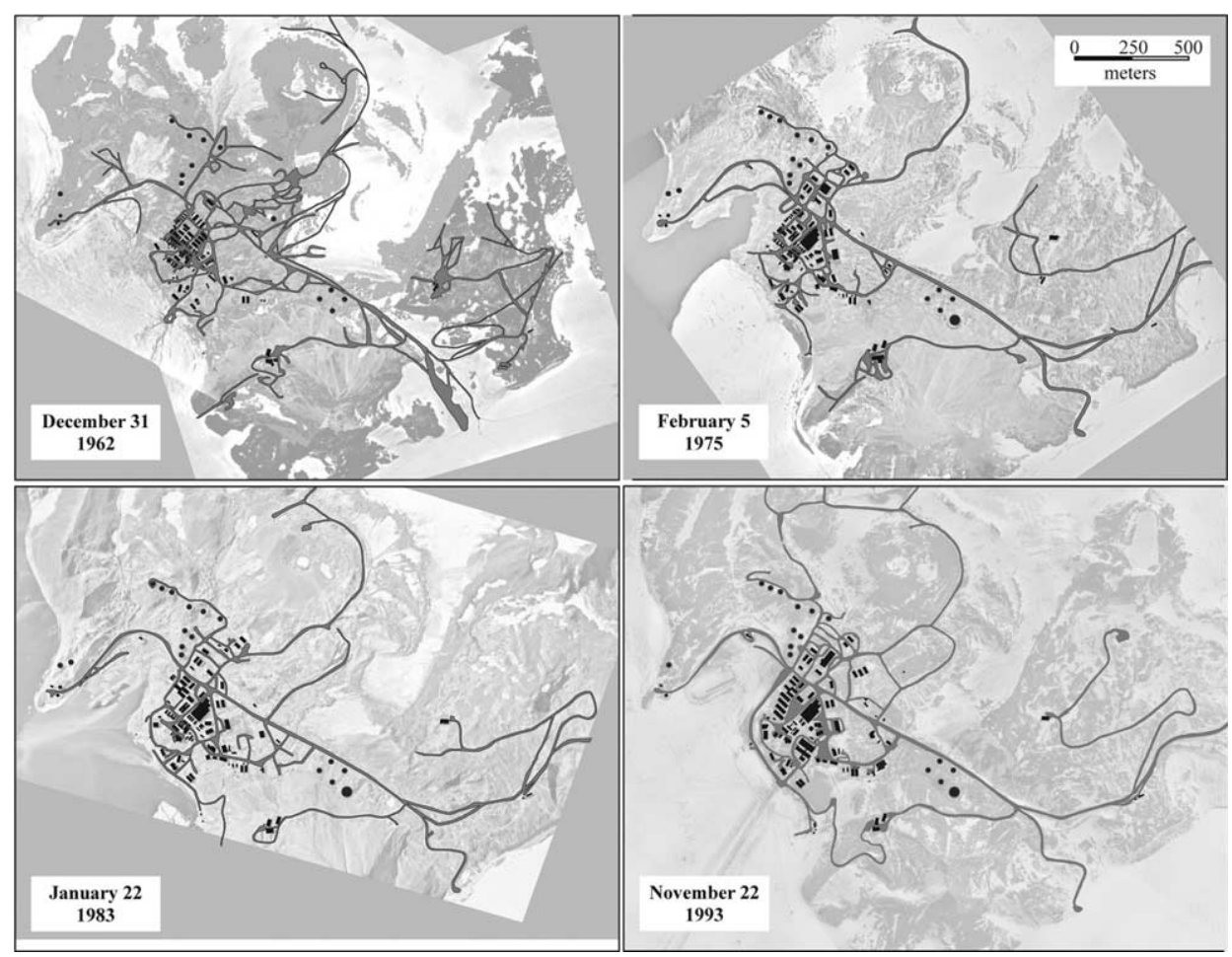

Figure 6. McMurdo Station's roads (gray), fuel tanks (dark gray) and buildings (black) in 1962, 1975, 1983 and 1993.

An area on Black Knob overlooking McMurdo has been occupied by a RADARSAT satellite tracking dome and support building since 1994. While this site did not previously contain any buildings it was already heavily disturbed by surface scraping (discussed in detail below). While McMurdo's building footprint has increased over time, an increase in building area does not necessarily represent an increase in the impacted area. Proposed plans should lessen the number of areas where buildings exist in the future.

\section{Fuel storage and transport}

As the logistical hub of USAP activities, fuel is a major potential source of contamination. Fuel storage at McMurdo is accomplished via a system of above ground steel bulk storage tanks. Historically, these bulk fuel storage tanks have been concentrated in three areas - Hut Peninsula, the hill above Winter Quarters Bay, and the pass on the east side of Observation Hill known as the Gap (Figure 7). Currently, fuel is piped from the bulk storage facilities to various needed localities (buildings, helicopter pad refueling station, fuel transfer points at Winter Quarters Bay, Scott Base and Williams Field) via 6700 meters of steel piping running above the ground on steel supports (ASA 1999). This steel piping replaced flexible fuel hoses used earlier in the station's history, however, flexible fuel hoses continue to be used to supply fuel to the airfields. Fuel transfer to the numerous smaller tanks located adjacent to buildings is via tanker truck. The locations and status of 


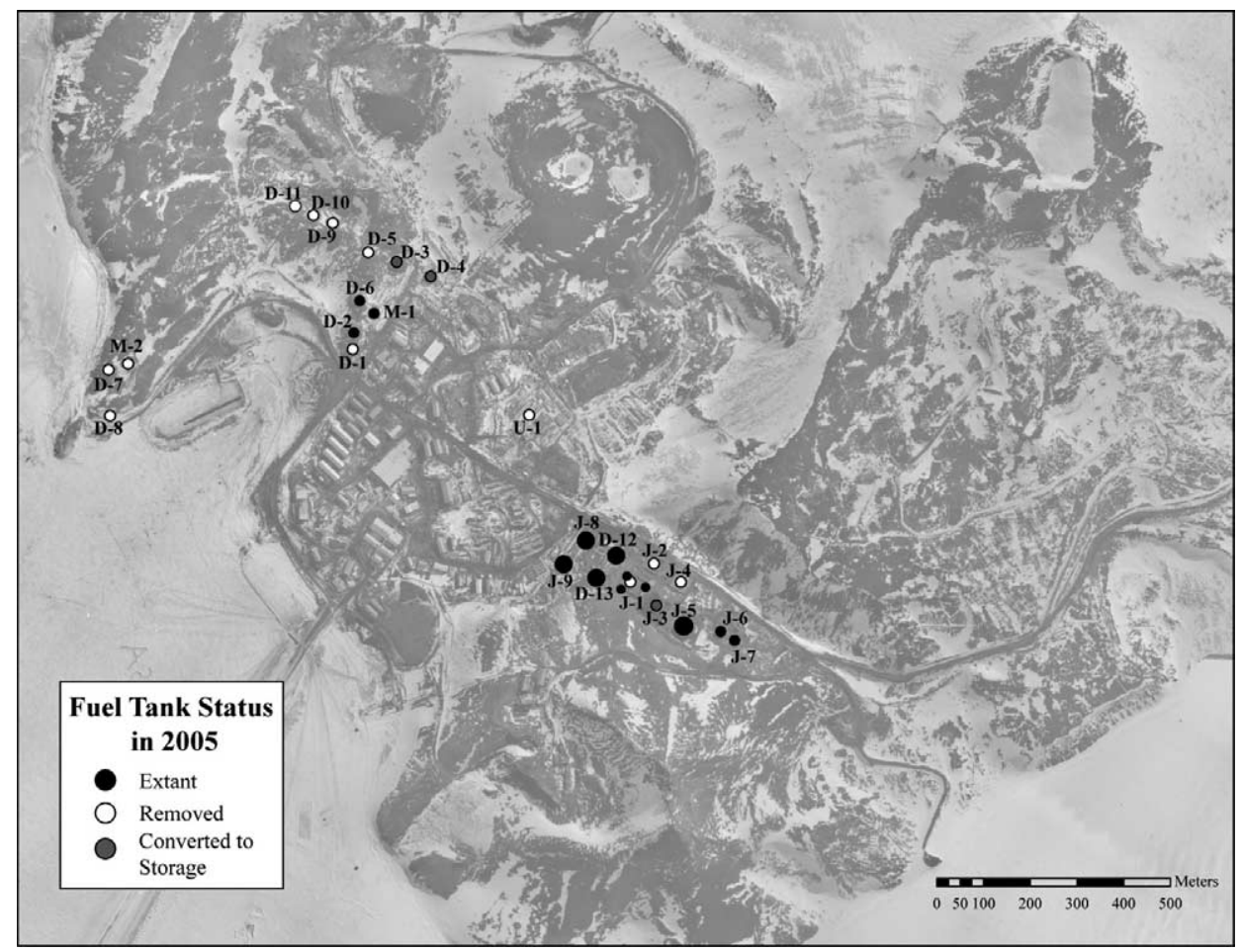

Figure 7. The current and historical location of bulk fuel storage tanks at McMurdo Station as of 2005 .

McMurdo's bulk fuel tanks is shown in Figure 7 and Table 2. This compilation is based upon written documentation, station facilities maps and aerial photography.

The majority of the fuel tanks in use at McMurdo were constructed in the period 1955-1968 and are at the end of their useful lifespan (ASA 1999). Beginning in the early 1990s, fuel storage at McMurdo began being consolidated into new storage tanks housed within containment berms in the Gap (Figure 2). Consequently, the configuration of fuel storage at McMurdo has and is undergoing major changes. Fuel tanks outside of 'The Gap' have or are being dismantled. A brief history of the fuel storage in each of the three major tank farms follows. In addition to the three main clusters of fuel tanks, a lone fuel tank (tank U-1 in Table 2) was constructed in the cargo yards prior to 1960 . This tank was removed by 1970, the same year that Tank D-6 was constructed above Winter Quarters Bay.

From the early 1960s to early 1990s, fuel storage facilities existed within 30 meters of the Historic Discovery Hut. Prior to dismantling that began in 1991, these facilities on Hut Point included three bulk storage tanks, a pump house and associated piping. These facilities aided in the offloading of fuel from the tanker during McMurdo's annual refueling operation. Fuel transfer operations have utilized both Winter Quarters Bay and Arrival Bay. During the 1991-1992 austral summer season two tanks were removed from the Hut Point Peninsula. The remaining tank, pumphouse, and associated piping were removed in the 1996-1997 austral summer. 
Table 2. McMurdo bulk fuel tank characteristics and the year constructed and removed as determined from aerial photography and station maps.

\begin{tabular}{|c|c|c|c|c|c|}
\hline Name & Fuel type & $\begin{array}{l}\text { Capacity } \\
\text { (gallons) }\end{array}$ & Status as of 2005 & $\begin{array}{c}\text { Year } \\
\text { constructed }\end{array}$ & $\begin{array}{c}\text { Year } \\
\text { removed }\end{array}$ \\
\hline D-1 & JP-8 & 250,000 & Removed & 1960 & 1999 \\
\hline D-2 & JP-8 & 500,000 & Extant & 1960 & \\
\hline D-3 & JP-8 & 500,000 & Converted to storage 2003 & 1962 & \\
\hline $\mathrm{D}-4$ & JP-8 & 500,000 & Converted to Storage 2003 & 1962 & \\
\hline D-5 & JP-8 & 250,000 & Extant & 1962 & 2003 \\
\hline D-6 & JP-8 & 500,000 & Extant & 1970 & \\
\hline D-7 & JP-8 & 250,000 & Removed & 1960 & 1996 \\
\hline D-8 & JP-8 & 100,000 & Removed & 1960 & 1993 \\
\hline D-9 & JP-8 & 500,000 & Removed & 1962 & 2003 \\
\hline $\mathrm{D}-10$ & JP-8 & 500,000 & Removed & 1965 & 2003 \\
\hline \multirow[t]{2}{*}{ D-11 } & JP-8 & 500,000 & Removed & 1965 & 2003 \\
\hline & & 500,000 & Converted to storage 2003 and & 1962 & 2004 \\
\hline $\mathrm{J}-1$ & JP-8 & & later removed & & \\
\hline $\mathrm{J}-2$ & JP-8 & 250,000 & Removed & 1960 & 2004 \\
\hline $\mathrm{J}-3$ & JP-8 & 500,000 & Converted to storage 2003 & 1960 & \\
\hline $\mathrm{J}-4$ & JP-8 & 250,000 & Removed & 1960 & 2004 \\
\hline $\mathrm{J}-5$ & JP-8 & $2,200,000$ & Extant & 1971 & \\
\hline $\mathrm{J}-6$ & JP-8 & 250,000 & Extant & 1993 & \\
\hline $\mathrm{J}-7$ & JP-8 & 250,000 & Extant & 1993 & \\
\hline M-1 & MOGAS & 250,000 & Extant & 1960 & \\
\hline M-2 & MOGAS & 100,000 & Removed & 1970 & 1993 \\
\hline $\mathrm{J}-8$ & JP-8 & $2,200,000$ & Extant & 1999 & \\
\hline $\mathrm{D}-12$ & P-8 & $2,200,000$ & Extant & 1999 & \\
\hline J-9 & JP-8 & $2,200,000$ & Extant & 2000 & \\
\hline D-13 & JP-8 & $2,200,000$ & Extant & 2000 & \\
\hline $\mathrm{N}-1$ & & 250,000 & Extant & 2005 & \\
\hline $\mathrm{N}-2$ & & 250,000 & Extant & 2005 & \\
\hline $\mathrm{N}-3$ & & 250,000 & Extant & 2005 & \\
\hline $\mathrm{U}-1$ & UNKNOWN & $500,000^{*}$ & Removed & 1960 & 1970 \\
\hline
\end{tabular}

*The volume of this tank was estimated based on its diameter.

By 1963, the hillslope above Winter Quarters Bay housed 10 bulk fuel storage tanks with capacities ranging from 250,000 to 500,000 gallons. All tanks in this area lack containment berms. In 1992-1993 one tank (M-1) was condemned and has not been used since. Another tank (variously designated M-2 or D-1) was demolished during the 1997-1998 austral summer. By 2003, four additional tanks on the hillslope had been removed (D-5, D-9, D-10, and D-11) and two others (D-3 and D4) had been converted to unheated storage.

Bulk fuel tanks have also occupied the area in the pass between McMurdo Station and Scott Base since early in the station's history. In 1962, four bulk storage tanks occupied areas in The Gap with a fifth tank (J-5) added by 1971. To accommodate the fuel capacity lost with removal of the tanks at Hut Point and above Winter Quarters Bay, additional tanks were added beginning with the construction of two 500,000 gallon tanks (J-6 and J-7) in 1993. During the 1998-1999 austral summer, two tanks (J-8 and D-12) with capacities of 2,200,000 gallons each were constructed and additional tanks (J-9 and D-13) with identical capacities were added during the 1999-2000 field season. Elastometric-lined containment berms will be constructed 
around the new tanks with high-density polyethylene (HDPE) liners extending completely underneath the tanks. Since 2000 , fuel tanks J-1, J-2 and J-4 have been removed and $\mathrm{J}-3$ is currently serving as unheated storage. In addition, three new 250,000 tanks within containment berms have been erected on the site of former tank J-1 in 2004/2005.

Beginning in 1993, and continuing through the present, a substantial upgrade of existing fuel storage tanks and installation and upgrading of McMurdo's interconnecting fuel piping has been undertaken. This activity, which is nearing completion, will result in a reduced number of larger modern fuel tanks at McMurdo consolidated in a much smaller area than they occupied in the past. All remaining tanks will have secondary containment capable of containing $110 \%$ of the tank's capacity. As discussed above a major portion of this work was the construction of four new two million gallon tanks in 'The Pass.' Three smaller tanks have also been recently constructed.

In addition to new tanks, the piping used for fuel transfer around McMurdo is being substantially upgraded from flanged joints to welded joints to prevent leakage and new alarm systems will be installed. Secondary containment berms are also being constructed around smaller fuel tanks at the helicopter pad and other locations around the station.

As with buildings, all of the areas currently handling bulk fuel storage have been impacted by this activity since the early 1960s. Fuel storage has not grown monotonically through McMurdo's history (Figure 8). From 1956 until 1970, the number of bulk fuel storage tanks and volume of fuel storage grew rapidly. From 1970 to the early 1990s, bulk fuel storage at the station changed little. Major improvements in fuel storage have occurred beginning in 1993 with the dismantling of old tanks and more recent construction of larger new contained tanks. These new bulk storage facilities, while adding fuel storage capacity, will consolidate fuel storage in one area, and will result in a significantly smaller area of occupation by

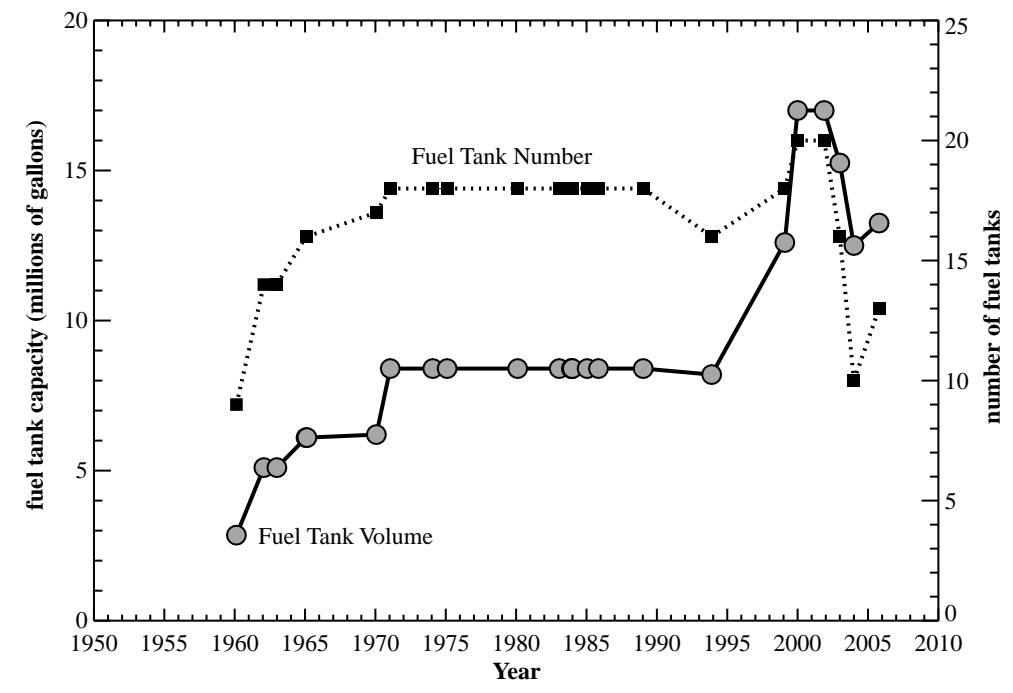

Figure 8. Changes in the number (black squares) and volume (gray circles) of bulk fuel tanks at McMurdo Station. 
this activity in the future than has been in the past. Figure 9 attempts to capture the changing configuration of fuel storage at McMurdo over its history.

\section{Roads}

The gravel road network surrounding McMurdo station consists of a single primary road connecting McMurdo Station to Scott Base and Williams Field. A series of secondary roads lead off the primary McMurdo-Scott Base road looping through central McMurdo, the cargo yards, and outlying areas such as Hut Point, Arrival Heights, Observation Hill, the T-site and the sea-ice transition zone. Within central McMurdo Station and the cargo yards, it is difficult to delineate roadways as they

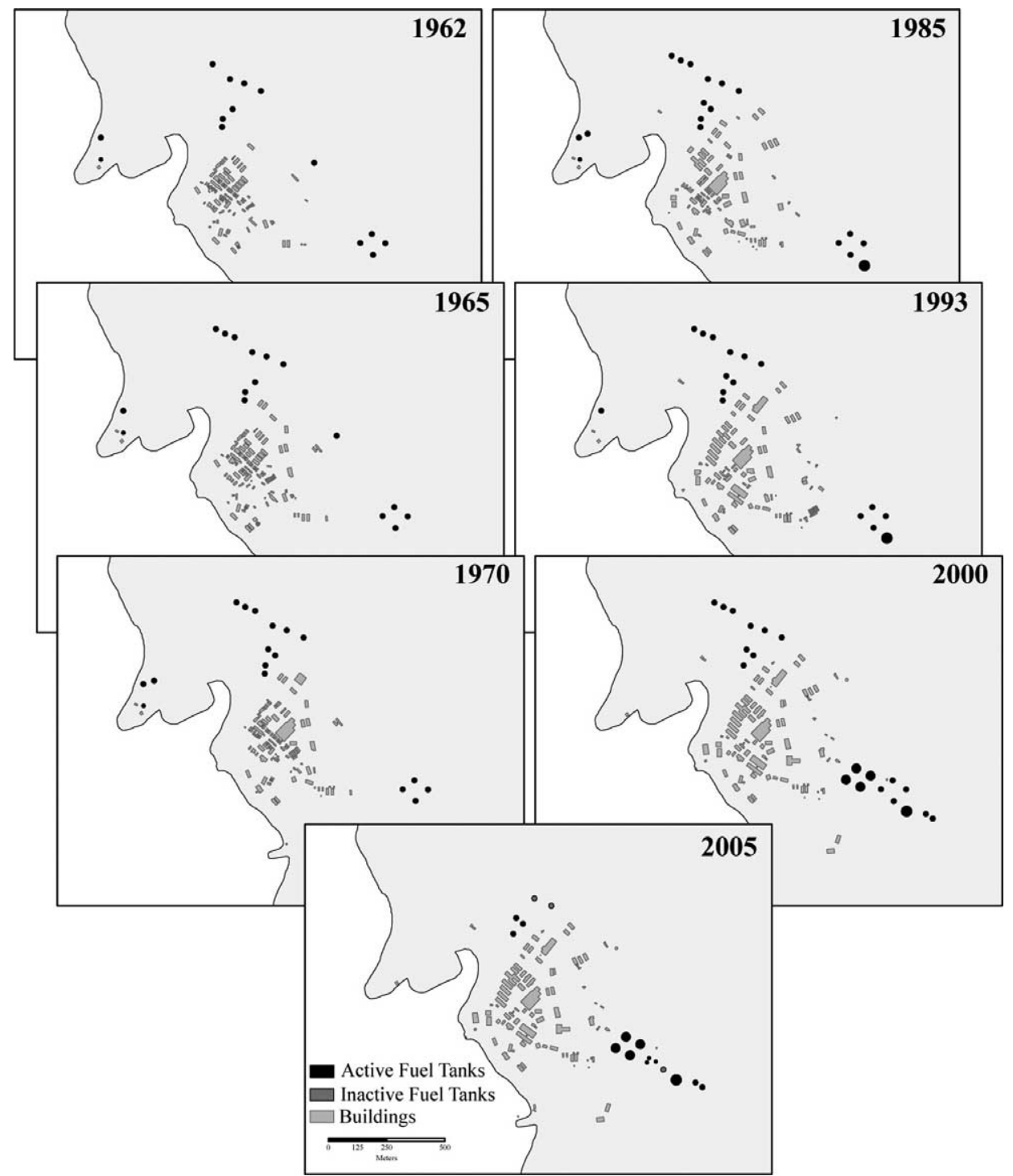

Figure 9. Location of bulk fuel storage tanks at seven periods in McMurdo's history. Fuel storage at present occurs in two of the three general areas historically used for fuel storage. 
grade seamlessly into storage and parking. As aptly stated in the McMurdo Facilities Manual (ASA 1999) "generally any relatively level area wide enough for a vehicle is considered a roadway if necessary." This approach makes delineating active roadways on aerial photographs by necessity a subjective process. Nevertheless, at several times throughout McMurdo's history it is possible to map major active roadways (Figures 6 and 10), which provides an indication of areas impacted by vehicles both at present and in the past.

As with other infrastructure, McMurdo's road network did not grow gradually over the station's history, but rather grew rapidly during the late 1950s and early 1960s. Subsequently, changes to the road network have been much smaller than occurred during the roadway's initial development. By 1962 (Figure 10a), much of McMurdo's current road network was largely in place. By 1966-1967, the road connecting McMurdo with Scott Base and runways on the Ross Ice Shelf was completed. Prior to this time, the primary road ran through the current "snowdump" east of Observation Hill and onto the sea ice.

In the late 1950s and early 1960s, vehicular traffic overall was more dispersed than at present. Individual roadways were less well defined and more numerous than at present with many small vehicle paths running through cargo storage areas (Figure 6). In the late 1950s and early 1960s, the primary road through The Gap was less well defined with several trackways in active use which is quite identifiable in snowcovered areas. By the mid 1960s, traffic though the pass appears largely confined to a single roadway. A portion of the road to Arrival Heights and an early access loop through Fortress Rocks were in place by 1962. In the mid 1970s, the road network was similar to the present network.

Early in the station's history a number of long single bulldozed paths ran through some of the more remote areas of the station, including the T-site and on Twin Craters and Arrival Heights. While some of these paths appear to terminate in areas actively being scraped for fill, the destination of others is unclear. From the aerial photographs it is impossible to ascertain whether some of these paths received any subsequent traffic or simply represented a single trip. Early in the station's history there also appears to have been more vehicular traffic over both snow and ice cover. In the late 1950s and early 1960s vehicle pathways are clearly visible and extend well up on the glacier lying between the cargo yard and the T-site, although it is not possible to determine if these terminated on the glacier or reached the T-site.

The current road to the former nuclear reactor and other buildings on the western slope of Observation Hill was completed by 1962. The secondary approach to Observation Hill from below the helicopter pad appears to have grown in a somewhat piecemeal fashion beginning in the 1960s. A track from buildings on Observation Hill to the sea ice was constructed by 1962, but the first aerial photograph showing connection to the helicopter pad was in 1983. The roadway is currently blocked above the helicopter pad, but the roadway is still visible in 2000 and later images.

Several other previously used roadways have also been abandoned. By 1965, a roadway loop, servicing the fuel pump house and tanks, once entirely encircled the historic Discovery Hut. In the upper portions of the "snowdump," the remains of an older road lie below the current main McMurdo-Scott Base road. Access to the Tsite itself has been accomplished via at least three different paths in the past and the remains of these abandoned roadways remain visible in aerial photography today. 
(a)

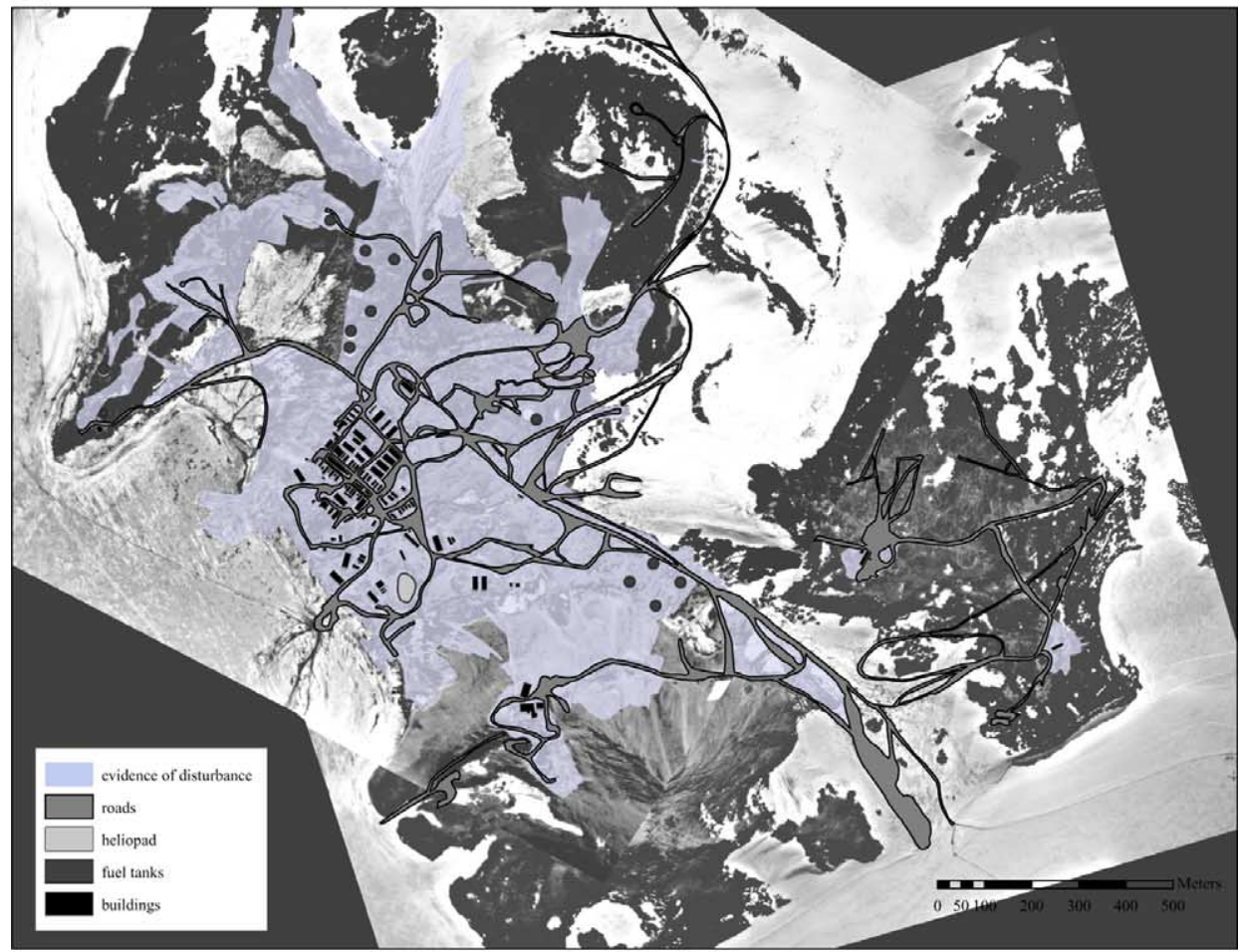

(b)

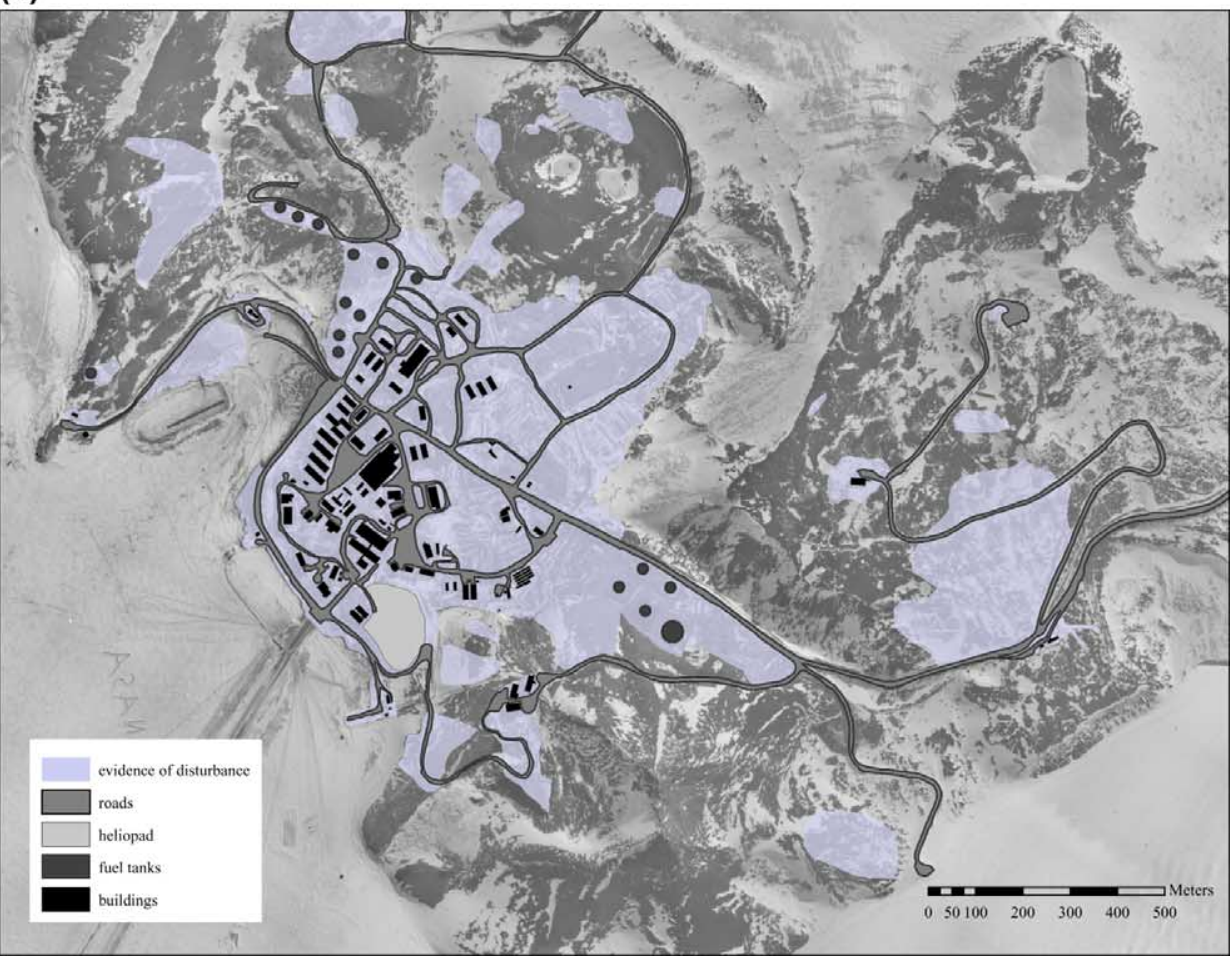

Figure 10. (Caption on p. 140) 
In conclusion, with some exceptions the road network in existence today is quite similar to that in place by 1967 so that most of the physical disturbances associated with road building occurred early in the station's history. Station activities since the 1990s do not appear to have dramatically increased the area impacted by roads.

\section{Disturbance}

Originally, much of the surface around McMurdo was also covered with a deflation lag. A deflation lag surface (stone pavement) is the residual accumulation of coarser particles at the surface as the finer particles have been removed by wind or other deflation processes (Cooke 1970; Mackay and Burn 2005; Nickling and McKenna Neuman 1995). Its presence at Winter Quarters was first recorded by Ferrar (1905) who noted that "Around Winter Quarters the bare land surfaces were usually covered by a loose cloak of rock debris quite 6 inches thick." Many ice-free lowland areas of the McMurdo Sound Region, including areas in the southern portion of Ross Island, were formerly covered with a ubiquitous periglacial feature - a microrelief pattern of polygons (Péwé 1959; Taylor 1922). These polygons are typically 6-12 m (20-40 feet) in diameter and separated by a set of interlocking polygonal trenches 8-45 cm (3-18 inches deep). Péwé (1959) completed a preliminary study of these features and proposed the term "sand-wedge polygon" for these features. The presence of sand-wedge polygons at McMurdo was described and photographed by Taylor (1922). Oblique trimetrogon photographs of the station taken soon after its inception in 1956 show extensive sand-wedge polygons at McMurdo (Figure 3). Incidentally, Péwé (1959) used this photograph as his illustration of McMurdo Sound sand-wedge polygons.

Much of the deflation lag and sand-wedge polygons in areas immediately adjacent to McMurdo station has been altered during construction. Deflation lag has been removed for use as fill material. Such activities destroyed the sand-wedge polygons Péwé (1959) used for illustration purposes. However, destruction of these features, in combination with other evidence of surface modification, makes it possible to map changes in the "footprint" of physical disturbance at McMurdo. Illustrations of the areas of disturbance visible in 1962 and 1993 are shown in Figure 10. In addition to destruction of sand-wedge polygons, long-linear "windrows," left behind in the scraping process, are diagnostic of surface disturbance.

The timing of the first recorded observation of disturbance at McMurdo for fiveyear periods (excluding 1986-1990) is shown in Figure 11. Differences in spatial coverage and scale among aerial photographs means that in some cases a disturbance may have actually occurred some years before it was identified in an aerial photograph. Thus, the disturbance could actually be older but not younger in age then mapped. In addition, disturbance is often non-uniform within each hexagon. Especially in outlying areas, physical disturbance may impact only a fraction of a hexagon. Conversely, just because areas are not tagged as being disturbed does not mean they are entirely undisturbed, only that the disturbance to date has not left discernable evidence on aerial photographs. Some footpaths near

Figure 10. Areas with evidence of surface disturbance in (a) 1962 and (b) 1993. Areas of disturbance are identified by evidence of windrows or disturbance associated with buildings or cargo. Absence of disturbance on Crater Hill and Hut Point in 1993 does not indicate these areas have not been disturbed, simply that remediation efforts had removed many of the previously existing windrows. 


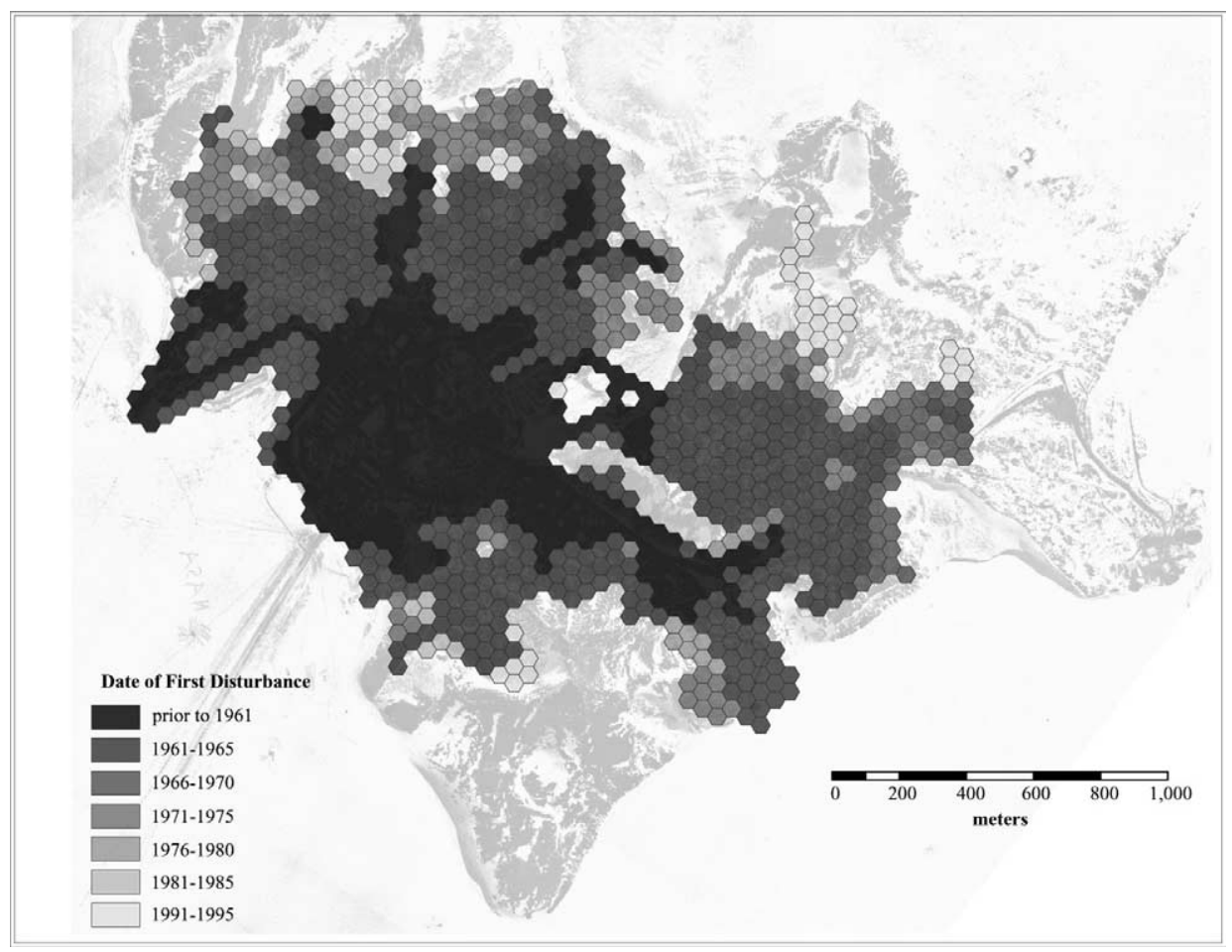

Figure 11. Year with first evidence of physical disturbance over McMurdo Station.

Cape Armitage, while occasionally visible on aerial photographs, have been neglected due to their small aerial extent. Despite minor problems, a consistent picture of physical disturbance at McMurdo Station emerges.

As shown in Figures 11 and 12, the rate of increase in disturbed area over the station's history has slowed dramatically. Beginning with the station's inception and continuing until 1970, continual and dramatic increases in the area of disturbance occurred. By 1960 most of what is now central McMurdo and cargo storage, as well as Hut Point and large portions of 'the Gap,' had already been disturbed. During the 1960s, disturbance continued to spread outward impacting large areas of Twin Craters and the plateau below Crater Hill. Eighty percent of the currently disturbed area had been impacted by 1970 . Since 1970, physical disturbance continued to occur on the periphery of earlier impacted areas, but its pace dramatically decreased. By 1993, the impacted area had reached over $2.5 \mathrm{~km}^{2}$. For comparison, the area of land hexagons covering the vast majority of McMurdo Station was $4.4 \mathrm{~km}^{2}$. At least half of the area around McMurdo station has experienced some sort of physical disturbance of the surface.

\section{Conclusions}

Aerial photographs of McMurdo acquired over the course of its history reveal that nearly 50 years of continuous station occupation has led to some degree of human impact over most of the ice-free areas at the southern end of the Hut Point Peninsula. The impact has not been spatially uniform nor has it been uniform through time. In the first two decades of the 20th century, the activities of British 


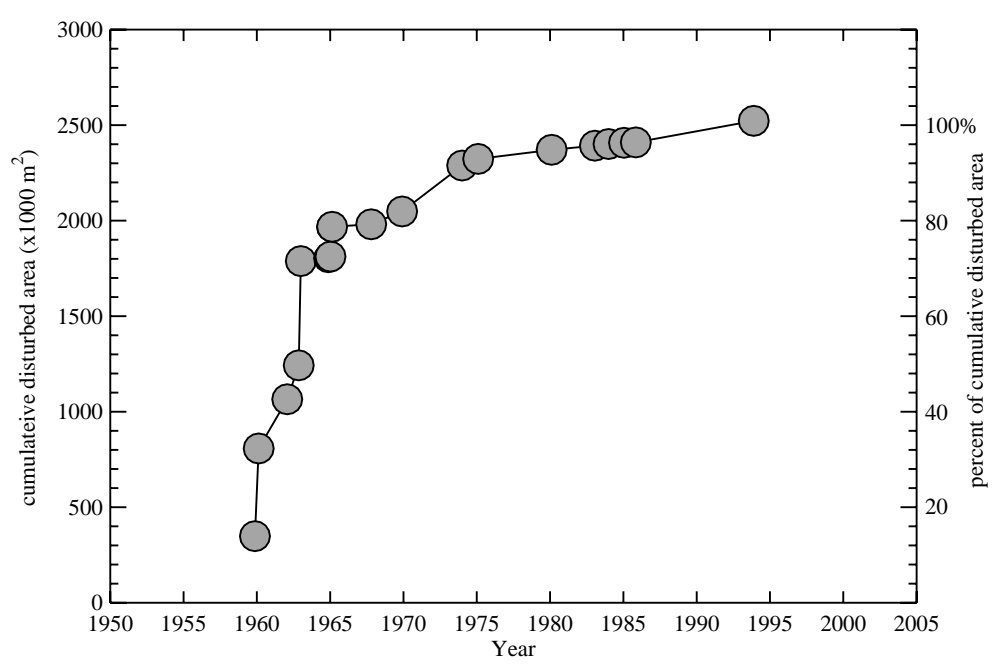

Figure 12. Cumulative area impacted by disturbance at McMurdo Station though time both as an area and as a percentage of total area impacted in 1993.

Antarctic expeditions did result in a small human impact. The establishment of permanent bases in the 1950s was accompanied by more intensive human impact. All the metrics examined here, which include the activities with the greatest impact on the local terrestrial environment, show consistent temporal patterns in human disturbance. Most importantly, the terrestrial footprint of McMurdo station has not grown monotonically through the station's history. Many of the areas observed to be impacted by human activities today were first impacted early in the station's history.

From McMurdo's inception in 1956 and continuing through the 1960s rapid station expansion occurred. Most heavily impacted areas were already heavily impacted by 1970. From 1970 until the early 1990s, the 'footprints' of buildings, roads, and fuel tanks changed at a much slower pace. While current station operations continue to modify the local landscape, for the most part they are confined to areas that were impacted in the first 10-15 years of the station's history.

Impacts of ongoing station activities are likely to be lessened in the future through improved pollution and spill prevention and remediation efforts as well as an extensive recycling program across the entire USAP. Beginning in the late 1980s considerable efforts were made in pollution prevention and waste management. Open burning has ceased, fuel handling and storage were improved and older and energy inefficient buildings continue to be replaced by larger more energy-efficient structures. Remediation of former waste storage areas continues and a new sewage treatment facility was brought online in 2003.

As of 1993, the Arrival Heights Antarctica Specially Protected Area and Site of Special Scientific Interest, while containing some buildings and roads, had experienced a lesser degree of physical disturbance then most other ice-free areas. Portions of the T-site and fairly inaccessible areas near Cape Armitage are also less impacted than other ice-free areas. As long as future construction and scraping activities are confined to the areas currently used for these purposes and do not 
impinge upon the Arrival Heights protected area, future station activities are unlikely to impact previously undisturbed areas.

Aerial photography provides a unique spatio-temporal perspective on the growth of McMurdo Station since its establishment in 1956 and helps place observed environmental impacts into their historical perspective. Moreover, the perspective provided by aerial photography is invaluable in characterizing the current environmental reference state. A thorough understanding of the present state of the environment is necessary for the prediction of future environmental impact of ongoing and proposed Antarctic activities as required by the Protocol on Environmental Protection to the Antarctic Treaty. Use of aerial photography in conjunction with GIS is an effective means of both assessing the reference environmental state prior to a proposed activity and monitoring the environmental impacts through time. High spatial resolution commercial satellites have proven to be a cost effective alternative to traditional aerial photography in providing timely image acquisition for environmental monitoring.

\section{Acknowledgements}

This work was funded by National Science Foundation Grant (OPP-9909445). The authors wish to acknowledge the tremendous support provided by all Antarctic support personnel who made this research possible. Guy Guthride (NSF) provided useful information on science support at McMurdo and Patrick Haggerty (NSF), provided information on the planned improvements to fuel storage infrastructure at the station.

\section{References}

AsA, 1999, McMurdo Station Facilities Manual (Englewood, Colorado: Antarctic Support Associates).

Beltramino, J.C.M., 1993, The Structure and Dynamics of Antarctic Populations (New York: Vantage Press).

Cole, J.W., Kyle, P.R. and Neall, V.E., 1971, Contributions to Quaternary geology of Cape Crozier, White Island and Hut Point Peninsula, McMurdo Sound Region, Antarctica. New Zealand Journal of Geology and Geophysics, 14(3), pp. 528-546.

Cooke, R.U., 1970, Stone pavements in deserts. Annals of the Association of American Geographers, 60, pp. 560-577.

Erb, K., U.S., 1999, Antarctic Research Program. House Committee on Science Subcommittee on Basic Research. Available online at: http://commdocs.house.gov/committees/science/hsy160140.000/hsy160140_0f.htm (accessed 07 November 2008).

Ferrar, H.T., 1905, Appendix I: summary of the geological observation made during the cruise of the S.S.'Discovery,' 1901-1904. In The Voyage of the 'Discovery' R.F. Scott (Ed.), pp. 437-468 (New York: Greenwood Press) (1969 reprinting).

Harris, C., 2001, Key pressures on Ross Sea environment: science. In Ross Sea Region 2001: A State of the Environment Report of the Ross Sea Region of Antarctica, E. Waterhouse (Ed.), pp. 3.7-3.8 (Christchurch, New Zealand: New Zealand Antarctic Institute).

JezeK, K.C. and Onstott, R.G., 1999, The role of remote sensing in the environmental monitoring of Antarctica. Polar Geography, 23(1), pp. 55-70.

MACKAY, J.R. and BuRN, C.R., 2005, A long-term field study (1951-2003) of ventifacts formed by katabatic winds at Paulatuk, western Arctic coast, Canada. Canadian Journal of Earth Sciences, 42(9), pp. 1615-1634. 
NeIder, C., 1974, Edge of the World Ross Island Antarctica (Garden City, New York: Doubleday \& Company).

Nickling, W.G. and MckennA, N.C., 1995, Development of deflation lag surfaces. Sedimentology, 42, pp. 403-414.

Office Of Polar Programs, 2003, United States Antarctic Program Summary and Background 2003-2004 Season, no. 18.

Peucker, T.K., Fowler, R.J., Little, J.J. and Mark, D.M., 1978, The Triangulated Irregular Network. Proceedings of the Digital Terrain Models (DTM) Symposium, St. Louis, 9-11 May, pp. 516-540.

PÉwÉ, T.L., 1959, Sand-wedge polygons (tesselations) in the McMurdo Sound Region, Antarctica - a progress report. American Journal of Science, 257, pp. 545-552.

Ross, J.C., 1847, A voyage of Discovery and Research in the Southern and Antarctic Regions, During the Years 1839-43. 2 Vols. (London: J. Murray).

ScotT, R.F., 1905, The Voyage of the 'Discovery' (New York: Greenwood Press) (1969 reprinting).

Shackleton, E., Sir, 1909, The Heart of the Antarctic: The Farthest South Expedition 1907-1909 (New York: Signet) (2000 reprinting).

Shackleton, E., 1919, South: The Endurance Expedition (New York: Signet) (1999 reprinting).

Sullivan, W., 1957, Quest for a Continent (New York: McGraw-Hill).

Taylor, G., 1922, The Physiology of the McMurdo Sound and Granite Harbour Region, British (Terra Nova) Antarctic Expedition (London: Harrison and Sons)).

US Department Of State, “Antarctic Treaty," 1 December 1959, TAIS no. 4780. online at Center for International Earth Science Information Network (CIESIN). 1996-2001. Environmental Treaties and Resource Indicators (ENTRI). Available online at: http://sedac.ciesin.org/entri/texts/acrc/at.txt.html (accessed 07 November 2008).

US Department Of State, Protocol on Environmental Protection to the Antarctic Treaty, 4 October 1991. XI ATSCM/2. online at Center for International Earth Science Information Network (CIESIN). 1996-2001. Environmental Treaties and Resource Indicators (ENTRI). Available online at: http://sedac.ciesin.org/entri/texts/antarctic. treaty.protocol.1991.html (accessed 07 November 2008).

Waterhouse, E., 2001, Ross Sea Region 2001: A State of the Environment Report of the Ross Sea Region of Antarctica (Christchurch, New Zealand: New Zealand Antarctic Institute). 